\title{
Measuring customer satisfaction in food industry
}

\author{
Parisa Akhtari $^{\mathrm{a}^{*}}$, Amir Parviz Akhtari ${ }^{\mathrm{b}}$ and Ahmad Torfi ${ }^{\mathrm{c}}$
}

${ }^{a}$ Msc, Management of Technology, Allameh Tabatabai University, Tehran, Iran

${ }^{b}$ Msc, Social - Economic Statistics, Shahid Beheshti University, Tehran, Iran

${ }^{c}$ Bsc, Chemical Engineering, Azad University, Omidieh, Iran

\begin{tabular}{l}
\hline C H R O N I C L E \\
\hline Article history: \\
Received October 28, 2014 \\
Received in revised format 15 \\
January 2015 \\
Accepted 28 January 2015 \\
Available online \\
January 312015 \\
\hline Keywords: \\
Customer Satisfaction \\
Customer Satisfaction Index \\
Bonny Chow National \\
Distribution Company of \\
Khuzestan \\
\hline
\end{tabular}

\section{A B S T R A C T}

\begin{abstract}
Customers are financial and intellectual capital of the firm and its survival and success depend on the attitude and firm performance to its customers. The goal of this article is to study customer satisfaction in Bonny Chow National Distribution Company and offering a model to evaluate customer satisfaction and also to study strength and weakness to improve and facilitate the defects. This study is descriptive, because it collects data and analyzes hypothesis based on expert survey. The questionnaire used in this paper has 10 questions on measure customer satisfaction. The results show that responders were satisfied with the visitors and delivery personnel and they were dissatisfied with the firm. In other words hypothesis 1 and 2 were accepted and hypothesis 3 was rejected.
\end{abstract}

(C) 2015 Growing Science Ltd. All rights reserved.

\section{Introduction}

Customers are financial and intellectual capital of the firms and their survival and success depend on the attitude and firm performance to clients. Therefore, planning for deep realizing of meeting recent and future requirements of customers and also providing products with quality higher than their expectations have become the approach of many pioneering companies (Moharami, 2008). Companies should improve their performances to satisfy their customers, so they can achieve competitive advantage in a competitive environment because loyalty is the primary result of customer satisfaction (Fani et al., 2011). Kalleh is one of the most popular diary brands in Iran. This company is going to promote its relationships with the customers to improve products quality and also to promote end users' satisfaction to increase its market share in competitive market. All Subsidiaries of Kalleh have this approach in their programs. Bonny Chow is the national distribution firm of Kalleh Products in Southwest provinces including: Khuzestan, Ilam and Hamedan. The primary objective of this study is to evaluate customers' satisfaction, the market of supermarkets, and to recognize strengths and

*Corresponding author. Tel: +989108000199

E-mail addresses: angelsa1365@gmail.com (P. Akhtari)

C 2015 Growing Science Ltd. All rights reserved. doi: $10.5267 / \mathrm{j} \cdot \mathrm{msl} .2015 .1 .016$ 
weakness to go up this satisfaction. In this paper, first, we define customer satisfaction concept, different methods and models for evaluating satisfaction; finally, we pursue the criteria to estimate it.

\section{Material and Methods}

\subsection{The importance of Customers Satisfaction}

Recently, we always hear about customers and their satisfaction, in fact, why should the firms pay attention to Customers Satisfaction? Reasons mentioned below indicate the importance of this issue:

1. Finding new customers costs 5 times keeping previous ones.

2. Solving customers' problems increases their loyalty.

3. Although improving customers' satisfaction increases the costs by $1-2 \%$, it raises the profit by $10-$ $25 \%$.

4. Satisfied customers definitely buy again and again.

5. Satisfied customers are the cheapest and the best economic consultants.

6. Providing appropriate service to customers is more effective than the most expensive posters and advertisements.

7. Nothing is more convincing than satisfied customers for other ones.

8. If we help our customers honestly, we would see everyone talks about our products and services.

\subsection{The concept of Customer Satisfaction}

Customer Satisfaction is one of internal actions of the firms, which represents their orientations toward meeting customers' requirements for improving quality of the products and service. According to Juran, customer satisfaction is a mood in which the customer feels product characteristics are complied with his/her expectations and dissatisfaction is a mood in which the defects of the product make the customer unhappy and critic. In another definition, customer satisfaction is a reaction from user after purchasing a product or a service. Lingfield defines psychological characteristics of customer satisfaction and express it as a feeling which is the result of comparison between product quality and customer's need and also social expectation associated with the product or service.

Rup states that customer satisfaction is an individual approach derived from permanent comparison between real performance and firm's expected performance. Topfer believes that customer satisfaction does not necessarily depend on the type of activities or its position on the market. It depends on the firm ability in providing expected quality.

Oliver believes that customer satisfaction or dissatisfaction is the result of the difference between the expectations and perceived quality. Therefore, we can use following equation to evaluate customer satisfaction (Maleki \& Darabi, 2008).

Customer Satisfaction = customer's expectations - customer's perception of quality.

\subsection{The methods of Customer Satisfaction evaluation}

The organization requires to plan a method to evaluate its customer satisfaction. This method should have strong and structured infrastructure. It also has to define some criteria to do this. There are various methods to evaluate customer satisfaction. We introduce the most important ones.

\subsubsection{Kano Model}

During the past, customer satisfaction was observed on a single dimension structure. It means that higher quality perceived by customers makes higher satisfaction. Because meeting necessities of one product does not necessarily increase customer satisfaction; on the other hand, type and the level of customer's need influenced on perceived product quality and customer satisfaction. (Zhang \& Von 
Dran, 2001). Kano introduced a model named Kano Customer Satisfaction Model in 1984 which was capable of separating 3 types of attributes of a model, which influences on customer satisfaction. In fact, Kano model categorizes different attributes and qualitative attributes of a product into 3 categories. Each category represents one kind of its requirements. There 3 types of requirements are as follows: (Zanjirchi et al., 2011).

1. Basic attributes represent features, which are so basic to the product that our customers just expect them to work.

2. Performance attributes are specifications where there is a direct correlation between the degree of achievement and customer satisfaction. As a consequence firms tend to compete on these attributes, differentiating their products by spending more (or less) than their competitors on certain performance attributes.

3. Delight attributes represent the Unexpected - when we delight the customer by over-delivering or doing something out of the ordinary (Holst, 2012).

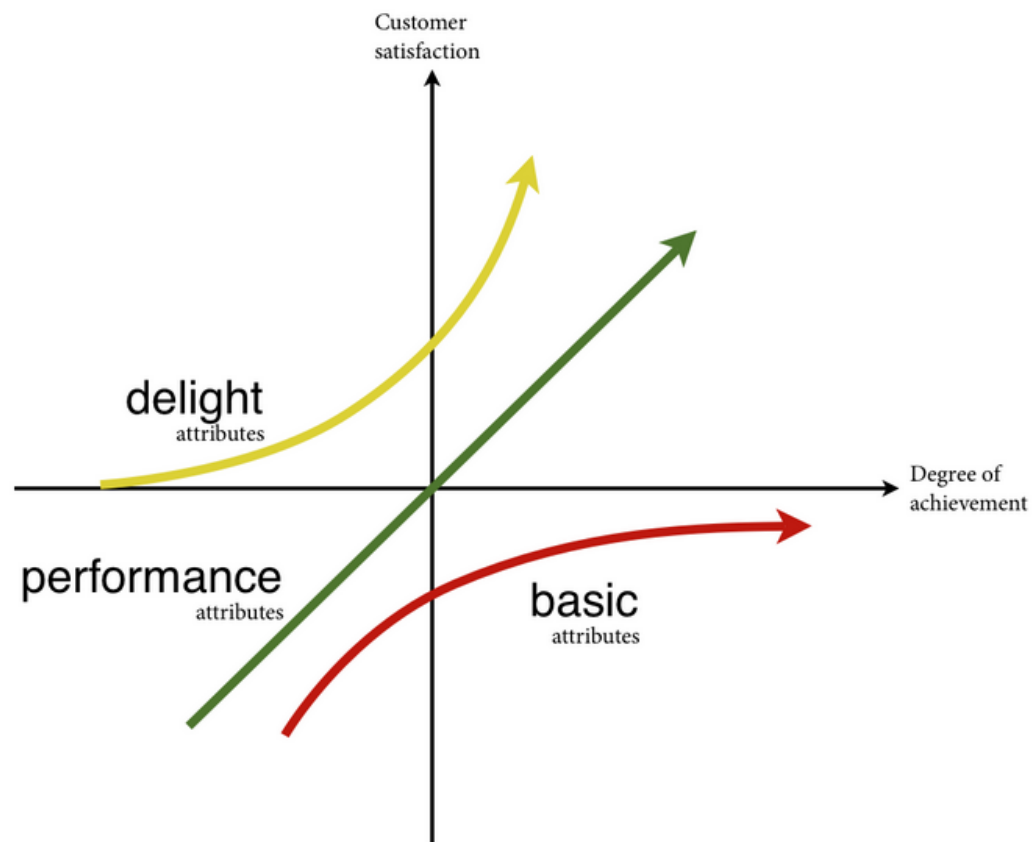

Fig. 1. Kano model

\subsubsection{Application of Kano model}

1. Customer Satisfaction has the highest dependency on this model.

2. This model has the highest proportion in the budget of market research.

3. This model promotes customers' need.

4. This model can moderate the competition among different organizations.

5. Success of this model depends on the correct implementation and definition of the criteria.

\subsubsection{Advantages of Kano model}

1. Better relationship with the customers,

2. Better understanding customers and their needs,

3. Final satisfaction of the customers,

4. Being a conceptual model. 


\subsubsection{Fornell Model}

Satisfaction index of Sweden was proposed by Fornell (1992) based on a structured model and customer poll and Fig. 2 demonstrates the summary of the proposed model.

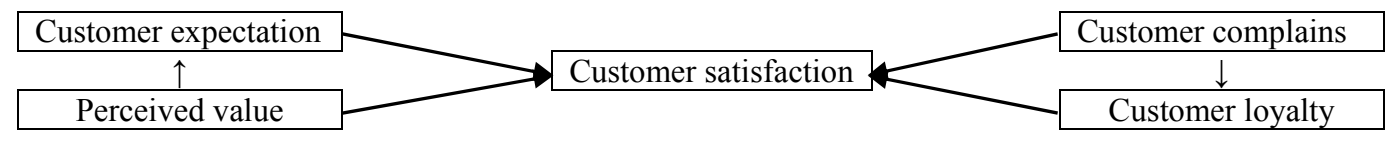

Fig. 2. Microstructure of customer satisfaction model of Sweden

\subsubsection{Macrostructure of customer satisfaction model of Sweden}

The important feature and index of this model is its ability to evaluate quality in wide scale and the possibility to make relationship between quality and customer behavior. This model was first implemented in The United States, and then Europe. Recently, there are differences in satisfaction indexes. This model is a conceptual model and concentrates on calculation of homogenization of customer expected index and judges on the basis of intuitive or emotional system of users/customers. As we can observe from the Fig. 2, there are various factors which influence customer satisfaction considered as a cause and effect relationship. Some of these factors are more important in customer satisfaction.

\subsubsection{Scamper Model}

The most substantial issue in Kano model is creation and innovation in providing service to customers. Osborn studied the basics of discovery, innovations and patents. He concluded that all innovations are on 7 components and Table 1 demonstrates 7 bases (Maleki \& Darabi, 2008).

\section{Table 1}

Innovations in Scamper model

\begin{tabular}{ll}
\hline Substitution & Question: What can be substitute of the X product? \\
Combination & Question: What can be combined with X? \\
Adaptation & Question: What can facilitate using X? \\
Magnification & Question: How can we get attention by magnifying X? \\
Putting to other uses & Question: What other uses does X have? \\
Elimination & Question: What can be removed from X? \\
Reverse & Question: If we reverse X, other uses would exist? \\
\hline
\end{tabular}

\subsubsection{SERVQUAL model}

This is a conceptual model of service suggested originally by Parasuraman et al. (1988) and it has become a standard instrument to assess quality of service called SERVQUAL. In service quality literature, primary research was about assessment of the problem after introduction of SERVQUAL model by Parasuraman et al. (1988). The primary focus was on determinative factors of service quality especially the process of providing service. SERVQUAL model has 5 dimensions: physical appearance, guaranty, reliability, responsibility and empathy. These 5 dimensions show American attitude to service quality. European attitude introduced perfectly in Gronroos Quality Service model. This model has the process with practical aspect or operational aspect and also technical output. 5 dimensions of 
SERVQUAL model are complied with operational quality in European model (Zivyar et al., 2012). Some of the dimensions of SERVQUAL model are as follows:

1. Tangibles: Physical facilities, equipment and appearance of personnel,

2. Reliability: Ability to perform the promised service dependably and accurately,

3. Responsiveness: Willingness to help customers and provide prompt service,

4. Assurance: Knowledge and courtesy of employees and their ability to inspire trust and confidence,

5. Empathy: Caring, individualized attention the firm provides its customers (Parasuraman et al., 1988).

\subsection{Experimental Background}

There are many studies about evaluation of customer satisfaction in Iran and all around the world. One research has been carried out named "comparative study of the focus on customer after implementation of quality improvement pattern in Social Security hospitals of Tehran" shows all studied hospitals have improved customers knowledge continuously in wide range of their processes and different parts of their organization. They also improved customer satisfaction (Mehrabi et al, 2005).

Mahdavi Nia (2005) studied customer satisfaction in $4^{*}$ hotels of Isfahan with the application of SERVQUAL model. The study was a descriptive - survey research and customer satisfaction was evaluated in Ali Ghapu and Setare Aseman hotels. The results showed that customers' perception of service quality was lower than expected level. Khodayari (2010) evaluated the employees and customers satisfaction in Saderat Bank of Iran and presented a pattern of psychological intervention to increase customers' satisfaction. Statistical society was Branches of Saderat Bank in Tehran and the results showed that the employees' satisfaction was on average and the customers were completely satisfied with the bank.

Sedghi et al. (2008) performed a comparative study on customer satisfaction index and offered a model to evaluate customers' satisfaction of Tax office. After factor analysis of data, the results showed that there were 5 categories of factors effective on the evaluation of customer satisfaction: expectation, employees, communication, rules and the culture. Derived model was confirmed by factor analysis. Finally, the model was analyzed on the basis of a questionnaire filled by taxpayers in Tax Office. The results showed that meeting requirements of taxpayers increases tax income of the organization.

\subsection{Customer Satisfaction Index}

All companies should improve their performance based on marketing and practical experiences to achieve competitive advantage in competitive environment because the main result of customer satisfaction is customer's confidence. Due to vital role of customers' satisfaction and their loyalty, analyzing the relationship among the variables are acceptable and should be compared among firms, organizations, industries and nationalities. Although marketing literature emphasizes on potential importance of confidence for customers satisfaction and their loyalty, this factor does not exist in national index. Confidence is an important factor in promoting customer loyalty. It seems that if one group trusts to other group, mutual positive behavioral intents will be created, therefore, when customers trust to a brand, they probably show positive attitude to that brand. To trust to a brand, customers should not only comprehend positive consequences but also they should believe that these consequences continue in the future.

\subsection{Positive correlation between Customers Satisfaction and confidence}

Recently various customer satisfaction indexes were estimated in product and service areas. The results of this evaluation facilitate finding the best and the most growing organizations in many countries and 
provide criteria to make strategic decisions to assess and to promote competition situation. The first national customer satisfaction index was Swiss Customer Satisfaction Barometer (SCSB) established in 1989. There has been many efforts in research and survey to improve practical perception of customer satisfaction evaluation. After public acceptance and understanding the importance of this index in Europe and USA, many countries started to determine national index such as European Customer Satisfaction Index (ECSI), Sweden Customer Satisfaction Barometer (SWICS), Norwegian Customer Satisfaction Barometer (NCSB), Malaysian Customer Satisfaction Index (MCSI), Chinese Customer Satisfaction Index (CCSI), South African Customer Satisfaction Index (SASI) and Turkish Customer Satisfaction Index (TCSI). A model has been established for Iranian Customer Satisfaction Index by studying literature, using American Customer Satisfaction Index, Johnson National Customer Satisfaction Index for Norway, Turkish Customer Satisfaction Index and also by using the model of Cater and Zabkar (Cater \& Zabkar, 2004). This model is shown in Fig. 3. Some assumptions are suggested for evaluating Customer Satisfaction (Fani et al, 2011).

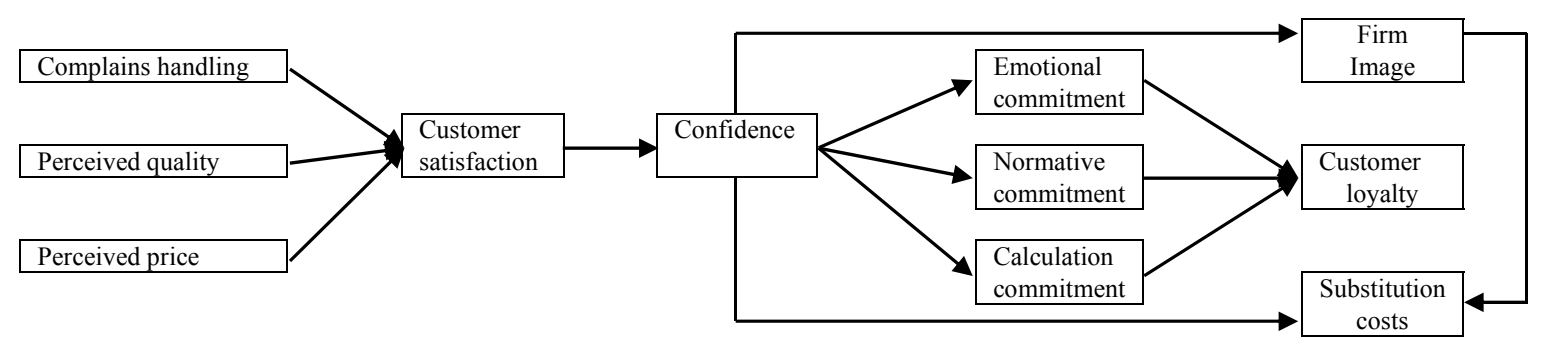

Fig. 3. The relationships between effective factors on Customer Satisfaction. (Iranian Model)

\subsection{Steps of Customer Satisfaction evaluation}

1. Determination of customer expectations,

2. Designing products and services based on customers' needs and expectations,

3. Production and delivery,

4. Managing customer expectations,

5. Evaluation of Customer Satisfaction (Abdoli \& Fereidun Far, 2009).

\subsubsection{Conceptual Model}

Bonny Chow is the national distribution company of Kalleh Diary products in 3 Southwest provinces of Khuzestan, Ilam and Hamedan. In this company, customers' orders are taken by the visitors and will be delivered by delivery personnel in 24 hours. In this paper, we study just supermarkets and no other markets such as restaurants. Therefore, the factors shown in the Fig. 4 are effective on Customer Satisfaction. In addition, some activities of the company are considered such as the method of financial settlements or the way of dealing with returned items (spoiled or defected products), quality and the price of the products are other factors which influence on Customer Satisfaction. Some of these factors are under the control of the firm and the others are not, the second ones depend on general policies of producing factory (Kalleh), it means that the distribution company (Bonny Chow) cannot change them.

According to explanation mentioned above, Bonny Chow Customer Satisfaction depends on 3 groups of factors: Visitors, Delivery personnel and the company performance. Each factor is divided into some factors which are shown in Fig. 4.

The process of Customer Satisfaction evaluation in this company has some stages. The first stage (Determining customers' expectations) is completed. Second stage which is delivery service has been also designed. We tried to train visitor and delivery personnel to improve their behaviors with customers and not to have ethical or functional problems with them. After these stages, Department of 
Customer Relationship started to evaluate Customer Satisfaction. The results will be discussed in next sections.

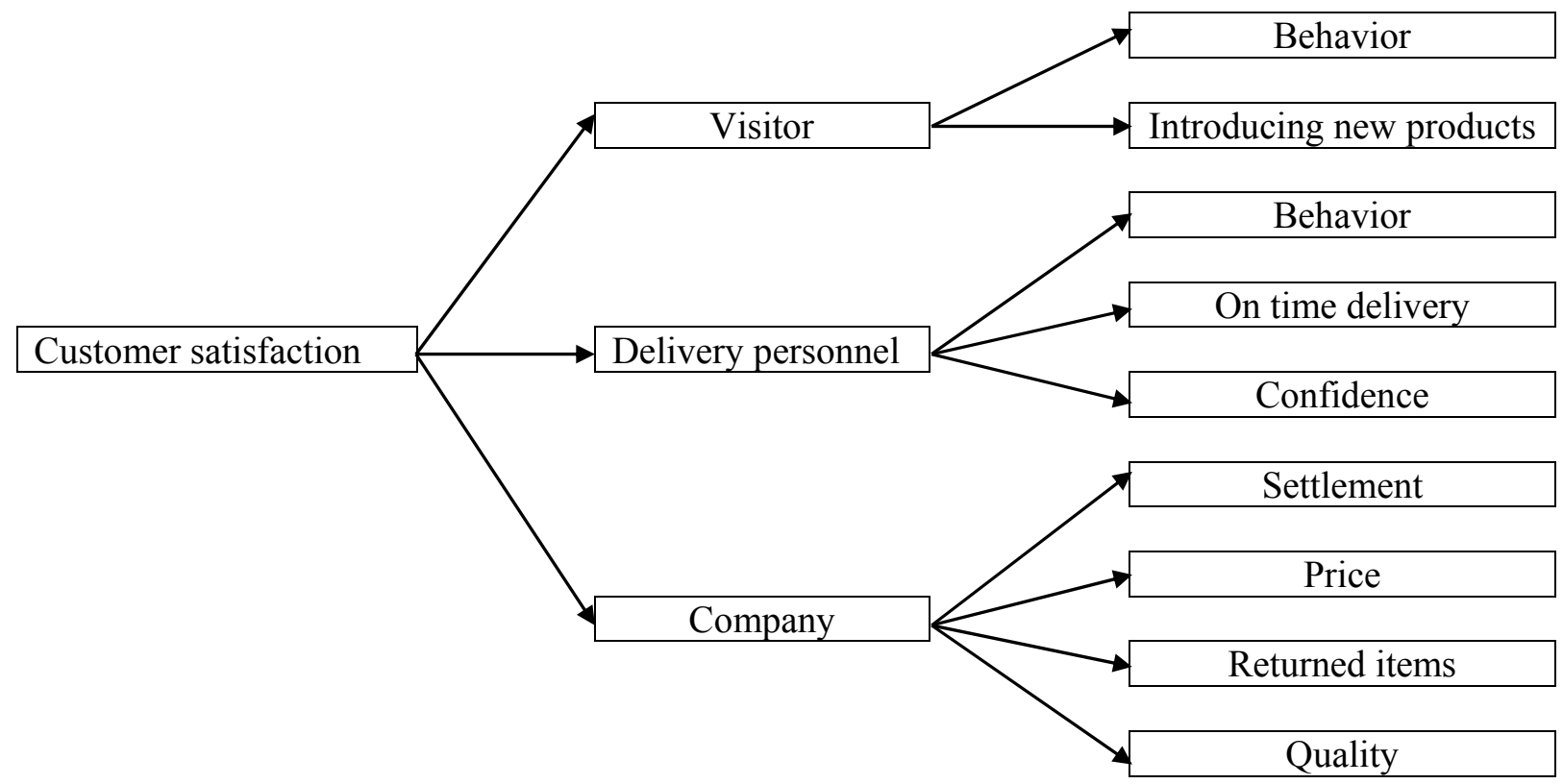

Fig. 4. suggested model to evaluate Bonny Chow Customers Satisfaction

\subsection{Problem statement}

This study is practical. The statistical society includes 2779 supermarkets in Ahwaz. According to Krejcie and Morgan sample size table, the number of samples is 330 . The method of sampling is random sampling. According to proportional allocation, 165 samples are selected from east area and 165 ones from west area (Ahwaz is divided to 2 areas in this paper). The data was selected by questionnaire. We use 4 options Likert scale. Validity of questionnaire is accepted by experts. According to Fig. 4 and the explanation about the importance and the ways of Customers Satisfaction Evaluation mentioned before, we established questionnaire consists of 10 questions, which includes effective factors on customers satisfaction.

Reliability of questionnaire is confirmed by Cronbach's alpha which is 0.68 . To analyze the results, we use descriptive statistics to study the hypothesis, we also use analytical statistics Mean Comparison or one sample t-test and Friedman test. Main hypothesis are as follows:

$\mathrm{H}_{1}$ : Customers are satisfied with the visitors.

$\mathrm{H}_{2}$ : Customers are satisfied with the delivery personnel.

$\mathrm{H}_{3}$ : Customers are satisfied with the company.

\section{Results}

$\mathrm{H}_{1}$ : Customers are satisfied with the visitors.

We use one sample t-test to test the hypothesis. In this test, we assume t-value as 3 (average level), in other words, if the average response is more than 3, the responders are satisfied with the visitors. The results of descriptive statistics to study satisfaction with the visitors in East and West areas are shown in Table 2. 
Table 2

The results of descriptive statistics of the Customer Satisfaction component with the visitors

\begin{tabular}{lccc}
\hline Area & Number of observes & Average & Standard Deviation \\
\hline East & 164 & 3.6768 & 0.63068 \\
West & 158 & 3.6614 & 0.66837 \\
\hline Total & 322 & 3.6693 & 0.64857 \\
\hline
\end{tabular}

The average responses show that satisfaction with the visitors is 3.67 in East area, 3.66 in West area and 3.66 in total. We find out visitors performance in both areas is near the same. In fact, customers are satisfied with the visitors. To prove the hypothesis, we describe t-test results. We use the following hypotheses by t-test.

$\mathrm{H}_{0}$ : Customers are not satisfied with the visitors in West and East areas $(\bar{X} \leq 3)$

$\mathrm{H}_{1}$ : Customers are satisfied with the visitors in West and East areas $(\bar{X} \geq 3)$

Table 3

The results of one sample t-test of customer satisfaction with the visitors

\begin{tabular}{rcccc}
\hline Area & $\mathrm{T}$ & Degree of freedom & Sig. & Mean-difference \\
\hline East & 13.739 & 163 & 0.00 & 0.67683 \\
West & 12.439 & 157 & 0.00 & 0.66139 \\
\hline Total & 18.517 & 321 & 0.00 & 0.66925 \\
\hline
\end{tabular}

Significant level resulted from one sample t-test indicates that the customers are greatly satisfied with the visitors. The results of descriptive statistics to study satisfaction with delivery personnel in East and West areas are shown in Table 4.

$\mathrm{H}_{2}$ : Customers are satisfied with the delivery personnel in East and West areas.

\section{Table 4}

The results of descriptive statistics of the Customer Satisfaction component with the delivery personnel

\begin{tabular}{cccc}
\hline Area & $\mathrm{N}$ & Average & Standard Deviation \\
\hline East & 164 & 3.6977 & 0.49099 \\
West & 158 & 3.6667 & 0.52165 \\
\hline Total & 322 & 3.6825 & 0.59571 \\
\hline
\end{tabular}

The average response show that satisfaction with the delivery personnel is 3.69 in East area, 3.66 in West area and 3.68 in total. We find out delivery personnel performance in both areas is near the same. In fact, customers are satisfied with the delivery personnel. To prove the hypothesis, we describe $t$ - test results.

$\mathrm{H}_{0}$ : Customers are not satisfied with the delivery personnel in West and East areas $(\bar{X} \leq 3)$

$\mathrm{H}_{1}$ : Customers are satisfied with the delivery personnel in West and East areas $(\bar{X} \geq 3)$

Table 5

The results of one sample t-test of customer satisfaction with the delivery personnel

\begin{tabular}{lllll}
\hline Area & T & Degree of freedor & Significant level & Mean difference \\
\hline East & 18.197 & 163 & 0.00 & 0.69766 \\
West & 16.064 & 157 & 0.00 & 0.66667 \\
Total & 24.216 & 321 & 0.00 & 0.68245 \\
\hline
\end{tabular}


Significant level resulted from one sample t-test indicates that the customers are greatly satisfied with the delivery personnel.

$\mathrm{H}_{3}$ : Customers are satisfied with the company.

We use one sample t-test to test this hypothesis. In this test, we assume t-value as 3 (average level), in other words, if the average response is more than 3 , the responders are satisfied with the company. The result of descriptive statistics to study satisfaction with the company is shown in Table 6.

Table 6

The results of descriptive statistics of the Customer Satisfaction component with the company

\begin{tabular}{cccc}
\hline Area & Number of observes & Average & Standard deviation \\
\hline East & 164 & 2.7927 & 0.50411 \\
West & 158 & 3.8586 & 0.44869 \\
\hline Total & 322 & 3.8251 & 0.47812 \\
\hline
\end{tabular}

The average response shows that satisfaction with the company is 2.79 in East, 2.85 in West and 2.82 in total. We find out the company performance in both area is near the same. In fact, customers are not satisfied with the company. To prove the hypothesis, we describe t-test results. We are going to prove one of the following hypotheses by t-test.

$\mathrm{H}_{0}$ : Customers are not satisfied with the company in West and East areas $(\bar{X} \leq 3)$

$\mathrm{H}_{1}$ : Customers are satisfied with the company in West and East areas $(\bar{X} \geq 3)$

Table 7

The results of one sample t-test of customer satisfaction with the company.

\begin{tabular}{ccccc}
\hline Area & T & Degree of freedom & Sig. & Mean difference \\
\hline East & -5.267 & 163 & 0.00 & -.20732 \\
West & -3.960 & 157 & 0.00 & 0.14135 \\
\hline Total & -6.566 & 321 & 0.00 & -0.17495 \\
\hline
\end{tabular}

Significant level resulted from one sample t-test indicates that the customers are not satisfied with the company.

\section{Discussion Conclusion}

Firms' survival and their lives completely depend on the customers, so, realizing customers' recent and future needs, designing and planning to promote the requirements and providing better products with higher quality are the key points of success and survival of the firms in $21^{\text {st }}$ century. Companies should apply the principle of customer focus and other principles of quality management to promote their performance in competitive environment (Moharami, 2008). After determining effective factors on satisfaction of Bonny Chow Customers, statistical analyzes have shown that the customers were satisfied with the visitors and delivery personnel, but they were dissatisfied with the company. It means that hypothesis 1 and 2 are accepted and hypothesis 3 is rejected.

\section{Suggestions}

According to the results stated in previous sections, we find out main group of the customers of Bonny Chow (supermarkets) are not satisfied with the company, so, we should improve some activities in our organizations. Activities such as the method of financial settlements or the way of dealing with returned items (spoiled or defected products), quality and the price of the products. Since Kalleh is a popular 
brand in diary Industry in Iran, it is better to focus on the distribution channel of these products. Because they are the best marketer and the most appropriate units for suggesting Kalleh products to the end users. Therefore, we can review company activities such as the method of financial settlements or the way of dealing with returned items (spoiled or defected products), and we also can hold meeting with the customers and listen to their suggestions and complaints about quality, the behavior of the visitors and delivery personnel, price etc. Although all of these cases are not under the control of Bonny Chow Company, we can report the problems and suggestions to the factory or central office in Tehran. The last suggestion is to establish an online customer relationship management system that facilitates recording and analyzing the complaints to improve our performance. It also helps us to integrate our CRM systems.

\section{References}

Abdoli, K., \& Fereidunar, S. (2007). The pattern of customer satisfaction. Journal of Tadbir, 182, 3436.

Fani, P., Purmohammad, A., \& Hasan Zade, A. (2007). Presentation of Iranian customer satisfaction index. Report in Tarbiat Modares Unversity, 3-8.

Fornell, C. (1992). A national customer satisfaction barometer: The Swedish experience. the Journal of Marketing, 56(1), 6-21.

Holst, C. (2012). Kano Model. Address link: www.baymard.com, Visited on 10 April 2014.

Khodayari Fard, M. (2010). Psychometric characteristics of questionnaire of employees and customers satisfaction in Saderat Bank. Journal of Psychological Achievements of Chamran University, 2, 118.

Mahdavi Nia, H. (2005). Studying Customer Satisfaction in 4* Holtels of Isfahan by SERVQUAL model. M.Sc. Thesis, University of Economy and Administrative Science.

Maleki, A., \& Darabi, M. (2008). Various methods of evaluation of customer satisfaction. Journal of Automotive Engineering and Related Industries, 4, 3-6.

Mehrabi, F., Maher, A., \& Nasiri Pur, A. (2005). Level of focus on the Customers after implementing the pattern of quality improvement in Social Security hospitals of Tehran. Journal of Health Management, 20, 27-34.

Moharami, M. (2008). Customer focus and the solutions of its Institutionalization in organizations. Department of Technology and Science of Presidency, Special Committee on Nanotechnology Development.

Parasuraman, A ., Zeithaml, V., \& Berry, L. (1988). SERVQUAL: A multiple item scale for measuring consumer perception of service quality. Journal of Retainling, 64, 2-6.

Sedghi, A., Javadin, R., Matlabi, D., Hoseini, J., \& Yazdani, H. (2008). Comparative study of models of customer satisfaction index and offering a model to evaluate customers satisfaction of tax office. Journal of Business Management, 2, 101-118.

Zhang, P., \& Von Dran, G. (2001, January). Expectations and rankings of Web site quality features: Results of two studies on user perceptions. In System Sciences, 2001. Proceedings of the 34th Annual Hawaii International Conference on (pp. 10-pp). IEEE.

Zanjirchi, M., Ebrahim Zade Pezeshki, R., \& Arab, M.(2011). Kano model and its application in assessment of students needs. Fifth Conference of Quality Assessment in University System. 3-4.

Zivyar, F., Ziaee, M., \& Nargesian, M. (2012). Study of effective factors on Customer Satisfaction by SERVQUAL model. Journal of Modern Marketing Research, 3, 173-186. 